\title{
Hepatitis C Virus Infection Among Drug Addicts in Italy
}

\author{
T. Stroffolini, ${ }^{1}$ P.F. D'Egidio, ${ }^{2}$ A. Aceti, ${ }^{3}$ P. Filippini, ${ }^{4}$ M. Puoti, ${ }^{5}$ C. Leonardi, ${ }^{6}$ P.L. Almasio ${ }^{7 *}$ \\ and the DAVIS (Drug Addicted, HCV Prevalence in Italy: an Epidemiological, Observational, \\ Cross-Sectional, Multicenter Study) participating centers ${ }^{\dagger}$ \\ ${ }^{1}$ Department of Infectious and Tropical Diseases, Policlinico Umberto I, Rome, Italy \\ ${ }^{2}$ Addiction Service, AUSL Pescara, Italy \\ ${ }^{3}$ Department of Infectious Diseases, Sant'Andrea Hospital, University of Rome La Sapienza, Rome, Italy \\ ${ }^{4}$ Department of Public Medicine, Section of Infectious Diseases, 2nd University of Naples, Rome, Italy \\ ${ }^{5}$ Department of Infectious Diseases, AO Ospedale Niguarda Ca' Granda, Milano, Italy \\ ${ }^{6}$ Drug Addiction and Alcoholism Prevention and Treatment Operating Unit of the RMC Local Health Service of \\ Rome, Rome, Italy \\ ${ }^{7}$ Gastroenterology \& Hepatology Unit, Department of Internal Medicine and Biomedicine, Palermo, Italy
}

There is a lack of updated nationwide records regarding hepatitis $\mathrm{C}$ virus (HCV) infection among drug addicts in Italy. The prevalence and characteristics of HCV infection in a national sample of drug addicts in Italy were determined. Five hundred forty-three drug addicts (mean age 35.3 years, $85.1 \%$ males), selected from 25 Italian Centers for Substance Dependence were enrolled to be evaluated for antiHCV, HCV-RNA, HCV genotype, HBV markers, anti-HDV, and anti-HIV during the period of April-November 2009. Anti-HCV prevalence was $63.9 \%$. HCV-RNA was detected in $68.3 \%$ of patients positive for anti-HCV. Genotypes 1 and 3 prevailed $(49.3 \%$ and $39.7 \%$, respectively). However, $9.3 \%$ of the subjects had genotype 4 , a rate over threefold higher than the one observed in 1996 among drug addicts in central Italy. Needle sharing was the strongest independent predictor of the likelihood to contract an HCV infection (OR 8.9; 95\% Cl: 5.0-16.0). Only $19.3 \%$ of subjects received antiviral treatment for HCV. The prevalence of $\mathrm{HBsAg}$ and HIV positivity was $2.8 \%$ and $3.1 \%$, respectively. The pattern of HBV markers showed that nearly one-third of subjects had been vaccinated, while $42.3 \%$ were negative for any marker of $\mathrm{HCV}$. The prevalence of HCV infection is high among drug addicts in Italy. The incidence of Genotype 4 is increasing and this may lead to the spreading of the disease to the general population in the near future. Efforts should be made to improve the rate of antiviral treatment for drug addicts with HCV infection and vaccination against hepatitis B. J. Med. Virol. 84: 1608-1612, 2012. 단 2012 Wiley Periodicals, Inc.
KEY WORDS: HCV

\section{INTRODUCTION}

Intravenous drug use is one of the most efficient transmission routes of hepatitis C virus (HCV) infection. It is estimated that worldwide about 10 million (range: 6.0-15.2) intravenous drug users might be anti-HCV positive, and that many more are anti-HCV positive compared to the number of individuals with HIV infection [Nelson et al., 2011]. Despite the fact

Grant sponsor: Schering-Plough, SpA, Milan, Italy (now MSD Italia s.r.l., Rome, Italy).

A central laboratory was used for all virological tests: Diagnostica e Ricerca San Raffaele Spa, Milan, Italy (Laboraf).

†DAVIS Investigator Centres: Maria Chiara Pieri AUSL Bologna, Roberta Balestra ASS 1 Triestina, Alfio Lucchini ASL 2 Milan, Marco Riglietta ASL Bergamo, Vincenzo Marino ASL Varese, Emanuele Bignamini ASL 2 Turin, Lorenzo Somaini ASL Biella, Raffaele Lovaste APSS Trento, Felice Nava ULSS 8 Asolo, Pietro Fausto D'Egidio ASL Pescara, Paola Fasciani ASL Chieti, Fernando Cesarini ASL Rome A, Claudio Leonardi ASL Rome C, Milo Meini USL 5 Pisa, Francesco Ruffa ASL Florence, Mariano Pedetti AUSL 2 Umbria, Antonio D'Amore ASL 2 Caserta, Carmine Nigro ASL 3 Salerno, Roberto Buttazzo ASL Lecce, Antonello Taranto ASL Bari, Fernanda Magnelli ASP Cosenza, Guido Faillace ASL 9 Trapani, Michele Ferdico ASL 1 Agrigento, Franco Montesano ASP Catanzaro, Italy.

${ }^{*}$ Correspondence to: Prof. P.L. Almasio, Gastroenterology and Liver Unit, Dipartimento Biomedico di Medicina Interna e Specialistica (Di.Bi.M.I.S.), University of Palermo, Palermo, Italy.

E-mail: piero.almasio@unipa.it

Accepted 18 June 2012

DOI 10.1002/jmv.23370

Published online in Wiley Online Library

(wileyonlinelibrary.com). 
that drug users represent a wide segment of subjects with chronic HCV infection they are often excluded from treatment with interferon (IFN) because of concerns about adherence, re-infection, and IFN-mediated neuropsychiatric toxicity.

Italian data on HCV prevalence among drug addicts reveal a $32-84 \%$ range of HCV positivity [Stroffolini et al., 1997; Quaglio et al., 2003; Sereno et al., 2009]. Nevertheless, these data are either outdated or derived from local studies. Consequently, considering the complexity of the clinical management in this category of patients, it is important to define an updated epidemiological picture in Italy.

The aim of this study was to assess the prevalence and characteristics of HCV positivity among a representative national sample of drug addicts monitored by Services for Substance Dependence of the Italian National Health System. The prevalence of HBV, HDV, HIV, and their respective HCV coinfection were also evaluated.

\section{PATIENTS AND METHODS}

This multicenter, observational, cross-sectional study enrolled consecutive drug addicts (both intravenous and non-intravenous drug users) from 25 Italian rehabilitation centers distributed widely all over the country during the period of April-November 2009.

The study inclusion criteria were subjects aged 18to 65-year old who satisfied the criteria for substance dependence according to the Diagnostic Manual of Mental Disorders, Fourth Edition (DSM-IV-TR) [Diagnostic and Statistical Manual of Mental Disorders, 2000]. Exclusion criteria were alcohol dependence and participation in any other clinical study. The study consisted of a single visit during which all the studyrelated procedures were performed under the full control and responsibility of the Investigator. Procedures included the collection of demographic data, medical history, assessment, and evaluation of current and past drug addiction.

A written informed consent to study participation and to the treatment of personal data (according to the Italian Privacy law) was provided to all subjects by the investigator, and a specific form which was dated and signed by each patient was obtained before entering the study. Approval of the Ethics Committee was required from each site before the study began.

\section{Virologic Assays}

A $10 \mathrm{ml}$ blood sample was collected from each participant within 7 days of the study visit. Local laboratories performed the alanine aminotransferase (ALT) test. An aliquot of blood was stored at $-20^{\circ} \mathrm{C}$ and then sent to the study central laboratory Laboraf in Milan, Italy, for virologic assays. All samples were tested for HBV markers (HBsAg, HBeAg, anti-HBc, and anti$\mathrm{HBs}$ ), and anti-HCV using the Chemiluminescent Microparticle ImmunoAssay (CMIA) method (Architect, Abbott Laboratories, Abbott Park, IL). All samples were tested for anti-HDV by enzyme-linked immunosorbent assay (ELISA) method (test ETI-AB-DELTAK-2, Diasorin, Saluggia, Italy). Positive sera for HCV were tested for HCV-RNA by PCR (PCR realtime-detection limit $12 \mathrm{IU} / \mathrm{ml}$; Abbott Laboratories). HCV-RNA positive sera were further tested for genotyping that was obtained by direct sequencing of the $5^{\prime}$-untranslated terminal region ( $\left.5^{\prime} \mathrm{UTR}\right)$ gene of $\mathrm{HCV}$ followed by an analysis performed with a web-based automated genotyping program using BLAST, which can be found at http://www.ncbi.nlm.nih.gov/projects/ genotyping/formpage.cgi.

\section{Statistical Analysis}

Differences in proportion and means were calculated by chi-squared test or Student's $t$-test, respectively. A $P<0.05$ value was considered to be significant. A univariate analysis was used to estimate the crude odds ratios (OR) for the association between different variables and anti-HCV positivity. Adjusted OR were calculated by multiple logistic regression analysis [Kleinbaum et al., 1982] to identify independent predictors of the likelihood of anti-HCV positivity. In the logistic model, anti-HCV positivity was the outcome variable, while age, educational level, needle exchange, sexual partners of intravenous drug users, past detention, and intravenous use of heroin or cocaine were the independent variables. The reference category for estimates was that of the most favorable level of exposure.

\section{RESULTS}

A total of 558 subjects were enrolled and provided informed consent. Fifteen subjects were excluded from the analysis because of a missing anti-HCV test. Thus, the total number of subjects evaluated was 543 . Table I shows the baseline characteristics of the enrolled subjects. Almost all subjects were Caucasian $(98.0 \%)$ and mean age was 35.3 years. There was a clear male predominance $(85.1 \%)$. Subjects came from all over Italy with a slight prevalence of the northern regions. Only $3.5 \%$ had completed university studies. The majority (85.5\%) of subjects lived in households of no more than four people. Eighty-three percent went to their local rehabilitation center for substance dependence independently and were not referred by others. Only $7.6 \%$ of subjects had started drug abuse within the last 5 years. The subjects declared that, at the time of study, they were consuming heroin (59.5\%), cocaine $(45.7 \%)$, or cannabis $(47.0 \%)$.

Virologic assays showed that the prevalence of antiHCV positivity (including subjects with coinfections) was $63.9 \%$. HCV-RNA was detected in $68.3 \%$ of patients who were anti-HCV positive. Genotypes 1 and 3 prevailed (49.3\% and $39.7 \%$, respectively) even though the proportion of subjects infected by genotype 4 reached the rate of $9.3 \%$. The prevalence of HBsAg and anti-HIV positivity was $2.8 \%$ and $3.1 \%$, respectively. Of the $15 \mathrm{HBsAg}$ positive subjects, only one 
TABLE I. Baseline Characteristics of Subjects Included in the Study

\begin{tabular}{lc}
\hline Variable & $\mathrm{n}=543$ \\
\hline Age (years) (mean \pm SD) (range) & $35.3 \pm 8.6(18-62)$ \\
Gender & $462(85.1 \%)$ \\
Male & $81(14.9 \%)$ \\
Female & \\
Italian area of origin & $216(39.8 \%)$ \\
North & $149(27.4 \%)$ \\
Center & $178(32.8 \%)$ \\
South/Islands & \\
Education & $57(10.5 \%)$ \\
Elementary school & $317(58.4 \%)$ \\
Middle school & $150(27.6 \%)$ \\
High school & $19(3.5 \%)$ \\
College degree & \\
Family members & $464(85.5 \%)$ \\
$\leq 4$ & $79(14.5 \%)$ \\
>4 & \\
Referral pattern & $451(83.0 \%)$ \\
Volunteer & $38(7.0 \%)$ \\
Family & $27(5.0 \%)$ \\
Social services/police & $27(5.0 \%)$ \\
Other & \\
Time since first drug exposure & $41(7.6 \%)$ \\
$\leq 5$ years & $112(20.6 \%)$ \\
6-10 years & $198(36.4 \%)$ \\
11-20 years & $192(35.4 \%)$ \\
$>20$ years & $323(59.5 \%)$ \\
Current drug abuse ${ }^{\mathrm{a}}$ & $248(45.7 \%)$ \\
Heroin & $255(47.0 \%)$ \\
Cocaine & \\
Cannabis & \\
\hline
\end{tabular}

${ }^{\text {a }}$ Multiple reply.

(6.7\%) was HBeAg positive, and three $(20.0 \%)$ were co-infected with HDV. The percentage of $\mathrm{HBsAg}$ detected in subjects with anti-HCV positivity was $2.2 \%$, while the percentage of subjects positive for both anti-HCV and anti-HIV was $3.0 \%$ (Table II).

TABLE II. Virologic Characteristics of Subjects Included in the Study

\begin{tabular}{|c|c|}
\hline Viral marker & $\mathrm{n}=543$ \\
\hline Anti-HCV positive (including coinfections) & $347(63.9 \%)$ \\
\hline HCV-RNA positive ${ }^{\mathrm{a}}$ & $237(68.3 \%)$ \\
\hline HCV-RNA $\leq 600,000 \mathrm{IU} / \mathrm{ml}^{\mathrm{b}}$ & $134(56.5 \%)$ \\
\hline \multicolumn{2}{|l|}{ HCV genotypes ${ }^{\mathrm{c}}$} \\
\hline 1 & $117(49.3 \%)$ \\
\hline $1 \mathrm{a}$ & $56(47.9 \%)$ \\
\hline $1 b$ & $27(23.1 \%)$ \\
\hline $1 \mathrm{c}$ & $34(29.0 \%)$ \\
\hline 2 & $4(1.7 \%)$ \\
\hline 3 & $94(39.7 \%)$ \\
\hline 4 & $22(9.3 \%)$ \\
\hline HBsAg positive (including coinfections) & $15(2.8 \%)$ \\
\hline $\mathrm{HBeAg}_{\text {positive }}^{\mathrm{d}}$ & $1(6.7 \%)$ \\
\hline Anti-HDV positive $^{\mathrm{d}}$ & $3(20.0 \%)$ \\
\hline Anti-HIV positive (including coinfections) & $17(3.1 \%)$ \\
\hline Anti-HCV/HBsAg positive & $12(2.2 \%)$ \\
\hline Anti-HCV/anti-HIV positive & $16(3.0 \%)$ \\
\hline
\end{tabular}

${ }^{\mathrm{a}}$ In anti-HCV positive.

${ }^{\mathrm{b}}$ Data not available for all subjects.

'In HCV-RNA positive.

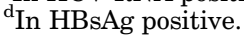

Table III shows a comparison of sociodemographic characteristics of subjects with HCV infection. AntiHCV positive subjects were more likely to be older (37.4 years vs. 31.6 years; $P<0.001$ ), with a low education level, and living in smaller households compared to participants not infected by HCV. Subjects with anti-HCV positivity also had a significantly longer duration of drug exposure and were more likely to report intravenous use of heroin and cocaine. Additional potential risk factors of exposure to HCV (exchange of needles or other drug paraphernalia, sexual partners of intravenous drug users vv. previous detention) were reported more frequently by subjects with anti-HCV positivity (Table IV). Eighty-seven percent of anti-HCV positive subjects were conscious of their liver disease, but only 67 out of 347 (19.3\%) anti-HCV positive subjects had received a specific antiviral treatment (data not shown).

Table V shows the crude and adjusted OR for the association between potential risk factors and antiHCV positivity. A univariate analysis of all variables versus anti-HCV positivity was performed. After adjustment for the confounding effect of all variables included into the model, we observed that age $>36$ years, needle exchange, past detention, intravenous use of heroin and cocaine all resulted as independent predictors of the likelihood of anti-HCV positivity. Low education level and intravenous drug user sexual partners were not associated with HCV infection.

Finally, the pattern of HBV markers among the 543 drug addicts was as follows: 230 subjects $(42.3 \%)$ were negative for all HBV markers, 15 (2.8\%) were HBV positive, $68(12.5 \%)$ displayed a resolved previous infection and were anti-HBs/anti-HBc positive, 44 (8.1\%) were anti-HBc positive only, and 186 (34.3\%) subjects who had been vaccinated against HBV were anti-HBs positive only.

\section{DISCUSSION}

This study provides a national picture of HCV infection among Italian drug users. Nearly two-thirds of the subjects included in this observational study were anti-HCV positive. The figures are similar throughout all the geographical areas suggesting a nationwide distribution of the issue. The majority of subjects had detectable HCV-RNA and nearly 50\% resulted as $>600,000 \mathrm{IU} / \mathrm{ml}$. As expected, a great percentage $(39.7 \%)$ of subjects was infected by genotype 3 . However, 9.3\% were infected by genotype 4 , a rate over threefold higher than the one observed in 1996 in a study performed in Central Italy [Stroffolini et al., 1997]. This increase in the past 13 years suggests that genotype 4 is spreading among drug users in Italy. Given that this group of subjects is relatively young, genotype 4 may further spread to the general population in the near future. Drug addiction seems to be the key factor for the introduction and spreading of genotype 4 in the western world [Schröter et al., 2002]. A French survey has shown that in Paris, 
TABLE III. Comparison of Demographic Characteristics of Subjects With HCV Status

\begin{tabular}{lcc}
\hline Variable & Anti-HCV positive $(\mathrm{n}=347)$ & Anti-HCV negative $(\mathrm{n}=196)$ \\
\hline Age (years) (mean \pm SD) & $37.4 \pm 8.1$ & $31.6 \pm 8.4$ \\
Gender & $296(85.3 \%)$ & $166(84.7 \%)$ \\
$\quad$ Male & $51(14.7 \%)$ & $30(15.3 \%)$ \\
Female & & \\
Italian area of origin & $132(38.0 \%)$ & $84(42.9 \%)$ \\
North & $97(28.0 \%)$ & $52(26.5 \%)$ \\
Center & $118(34.0 \%)$ & $60(30.6 \%)$ \\
South/Islands & & $15(7.7 \%)$ \\
Education & $42(12.2 \%)$ & $104(53.1 \%)$ \\
Elementary school & $213(61.4 \%)$ & $67(34.2 \%)$ \\
Middle school & $83(23.9 \%)$ & $10(5.1 \%)$ \\
High school & $9(2.6 \%)$ & $157(80.1 \%)$ \\
College degree & & $39(19.9 \%)$ \\
Family members & $307(88.5 \%)$ & $169(86.2 \%)$ \\
$\leq 4$ & $40(11.5 \%)$ & $9(4.6 \%)$ \\
P4 & & $11(5.6 \%)$ \\
Referral pattern & $282(81.3 \%)$ & $7(3.6 \%)$ \\
Volunteer & $29(8.4 \%)$ & $171(88.6 \%)$ \\
Family & $16(4.6 \%)$ & $22(11.4 \%)$ \\
Social Services/police & $20(5.7 \%)$ & 0.01 \\
Other & $150(44.4 \%)$ & 0.008 \\
ALT levels & $188(55.6 \%)$ & $<.2$ \\
Normal & & \\
Abnormal & & \\
\hline
\end{tabular}

${ }^{a}$ Data not available for all subjects.

genotype 4 is responsible for more than $10 \%$ of $\mathrm{HCV}$ cases [Payan et al., 2005]. Furthermore, a high prevalence of genotype $4(23.4 \%)$ has been found among HCV-infected Polish drug users [Chlabicz et al., 2008]. The distribution of HCV genotypes is of particular importance, since it represents a key factor of response to treatment. In fact, genotype 4 shows a lower response rate to antiviral treatment compared to genotype 3 [Khattab et al., 2011].

A major concern that emerged from this study is that only 1 out of 5 subjects with anti-HCV positivity had received a specific treatment for HCV infection. This is in contrast with recent studies that demonstrated a rate of sustained virologic response in drug addicts comparable to that achieved among non-drug addicts [European Association for the Study of the Liver, 2011].

As expected, the route by which a drug was administered influenced the rate of HCV positivity. Subjects reporting needle exchange are 9.2 times more likely to be anti-HCV positive than those who denied this practice.

In this cohort of drug addicts, the prevalence of HBV and anti-HIV positivity resulted unexpectedly low. Despite the fact that vaccination of drug users has been strongly recommended [Almasio et al., 2011] and offered free of charge in Italy since 1984, only one-third of these subjects were actually vaccinated against HBV. Therefore, approximately half of enrolled subjects were still susceptible to HBV and thus at risk of infection.

In conclusion, this observational study shows a high prevalence of HCV infection but low rates of other parenterally transmitted viruses among drug addicts in Italy. The prevalence of Genotype 4 is rising among this group of people, and, consequently, it might spread to the general population in the near future. Efforts should be made to improve the rate of

TABLE IV. Characteristics of Drug Addiction and Potential Risk Factors According to Anti-HCV Condition

\begin{tabular}{|c|c|c|c|}
\hline Variable & Anti-HCV positive $(\mathrm{n}=347)$ & Anti-HCV negative $(\mathrm{n}=196)$ & $P$-value \\
\hline \multicolumn{4}{|l|}{ Time from first drug exposure } \\
\hline$\leq 5$ years & $11(3.2 \%)$ & $30(15.3 \%)$ & $<0.001$ \\
\hline$\overline{6}-10$ years & $50(14.4 \%)$ & $62(31.6 \%)$ & \\
\hline $11-20$ years & $133(38.3 \%)$ & $65(33.2 \%)$ & \\
\hline$>20$ years & $153(44.1 \%)$ & $39(19.9 \%)$ & \\
\hline Intravenous use of heroin & $158(45.5 \%)$ & $27(13.8 \%)$ & $<0.001$ \\
\hline Intravenous use of cocaine & $90(27.7 \%)$ & $6(3.1 \%)$ & $<0.001$ \\
\hline Paraphernalia/syringe exchange & $194(56.1 \%)$ & $18(9.2 \%)$ & $<0.001$ \\
\hline Transfusion & $20(5.8 \%)$ & $8(4.1 \%)$ & 0.4 \\
\hline Intravenous drug user sexual partners & $108(31.1 \%)$ & $27(13.8 \%)$ & $<0.001$ \\
\hline Past detention & $129(37.2 \%)$ & $39(19.9 \%)$ & $<0.001$ \\
\hline
\end{tabular}

Multiple risk factors for the same subject. 
TABLE V. Factors Associated With the Probability of Anti-HCV Positivity

\begin{tabular}{llccc}
\hline Baseline characteristics & Comparison groups & Crude OR (95\% CI) & Adjusted OR (95\% CI) & $P$-value \\
\hline Age & S36 years versus $>36$ years & $4.02(2.76-5.87)$ & $3.00(1.92-4.69)$ & $<0.001$ \\
Education & High versus low & $1.79(1.24-2.60)$ & $1.44(0.89-2.34)$ & 0.14 \\
Paraphernalia/syringe exchange & Yes versus no & $12.54(7.39-21.28)$ & $9.22(5.22-16.26)$ & $<0.001$ \\
Intravenous drug user sexual partners & Yes versus no & $2.83(1.78-4.50)$ & $1.68(0.95-3.00)$ & 0.08 \\
Past detention & Yes versus no & $2.38(1.58-3.60)$ & $2.12(1.27-3.49)$ & 0.003 \\
Intravenous use of heroin & Yes versus no & $5.23(3.31-8.27)$ & $2.33(1.34-4.06)$ & 0.003 \\
Intravenous use of cocaine & Yes versus no & $11.09(4.75-28.88)$ & $5.65(2.19-14.57)$ & $<0.001$ \\
\hline
\end{tabular}

Crude and adjusted odds ratios (OR) derived from multiple logistic regression analysis.

antiviral treatment for drug addicts with $\mathrm{HCV}$ infection and vaccination against hepatitis $B$.

\section{REFERENCES}

Almasio PL, Babudieri S, Barbarini G, Brunetto M, Conte D, Dentico P, Gaeta GB, Leonardi C, Levrero M, Mazzotta F, Morrone A, Nosotti L, Prati D, Rapicetta M, Sagnelli E, Scotto G, Starnini G. 2011. Recommendations for the prevention, diagnosis, and treatment of chronic hepatitis $\mathrm{B}$ and $\mathrm{C}$ in special population groups (migrants, intravenous drug users and prison inmates). Dig Liver Dis 43:589-595.

Chlabicz S, Flisiak R, Kowalczuk O, Grzeszczuk A, Pytel-Krolczuk B, Prokopowicz D, Chyczewski L. 2008. Changing HCV genotypes distribution in Poland-Relation to source and time of infection. J Clin Virol 42:156-159.

Diagnostic and Statistical Manual of Mental Disorders. Fourth Edition-Text Revision (DSMIV-TR). Washington, DC: American Psychiatric Association (Pub.), 2000.

European Association for the Study of the Liver. 2011. EASL Clinical Practice Guidelines: Management of hepatitis C virus infection. J Hepatol 55:245-264.

Kleinbaum DG, Kupper LL, Chambless LE. 1982. Logistic regression analysis of epidemiologic data: Theory and practice. Commun Stat 11:485-547.

Nelson PK, Mathers BM, Cowie B, Hagan H, Des Jarlais D, Horyniak D, Degenhardt L. 2011. Global epidemiology of hepatitis B and hepatitis $\mathrm{C}$ in people who inject drugs: Results of systematic reviews. Lancet 378:571-583.

Payan C, Roudot-Thoraval F, Marcellin P, Bled N, Duverlie G, Fouchard-Hubert I, Trimoulet P, Couzigou P, Cointe D, Chaput
C, Henquell C, Abergel A, Pawlotsky JM, Hezode C, Coudé M, Blanchi A, Alain S, Loustaud-Ratti V, Chevallier P, Trepo C, Gerolami V, Portal I, Halfon P, Bourlière M, Bogard M, Plouvier E, Laffont C, Agius G, Silvain C, Brodard V, Thiefin G, Buffet-Janvresse C, Riachi G, Grattard F, Bourlet T, Stoll-Keller F, Doffoel M, Izopet J, Barange K, Martinot-Peignoux M, Branger M, Rosenberg A, Sogni P, Chaix ML, Pol S, Thibault V, Opolon P, Charrois A, Serfaty L, Fouqueray B, Grange JD, Lefrère JJ, Lunel-Fabiani F. 2005. Changing of hepatitis $\mathrm{C}$ virus genotype patterns in France at the beginning of the third millenium: The GEMHEP GenoCII Study. J Viral Hepat 12:405-413.

Quaglio GL, Lugoboni F, Pajusco B, Sarti M, Talamini G, Mezzelani P, Des Jarlais DC, GICS. 2003. Hepatitis C virus infection: Prevalence, predictor variables and prevention opportunities among drug users in Italy. J Viral Hepat 10:394-400.

Schröter M, Zöllner B, Schäfer P, Reimer A, Müller M, Laufs R, Feucht HH. 2002. Epidemiological dynamics of hepatitis $\mathrm{C}$ virus among 747 German individuals: New subtypes on the advance. J Clin Microbiol 40:1866-1868.

Sereno S, Perinelli P, Laghi V. 2009. Changes in the prevalence of hepatitis $\mathrm{C}$ virus genotype among Italian injection drug users-Relation to period of injection started. J Clin Virol 45: $354-357$.

Stroffolini T, Fiume A, Fatale G, Regni F, Ciccozzi M, Marzolini A, Mele A. 1997. Hepatitis C virus genotypes among intravenous drug users in Italy. Hepatol Res 9:20-27.

Khattab MA, Ferenci P, Hadziyannis SJ, Colombo M, Manns MP, Almasio PL, Esteban R, Abdo AA, Harrison SA, Ibrahim N, Cacoub P, Eslam M, Lee SS. 2011. Management of hepatitis C virus genotype 4: Recommendations of an International Expert Panel. J Hepatol 54:1250-1262. 